\title{
Socio-psychological profile of Latvian inhabitants who did not comply with the COVID- 19 epidemiological requirements
}

\author{
Gatis Upesleja $^{1}$ and Viktorija Perepjolkina ${ }^{1}$ \\ ${ }^{1}$ Riga Stradins University, Riga, Latvia
}

\begin{abstract}
Since the beginning of 2020, the world has been affected by the corona virus COVID-19. Since the spring, a number of nations around the world, including Latvia, have declared a state of emergency, with specific government restrictions developed in cooperation with WHO, to reduce spread of the COVID-19. The aim of this study is to examine socio-psychological profile of Latvian inhabitants who did not comply with the COVID-19 epidemiological requirements. A randomized nationally representative sample $(N=2608$, aged from $18-74$, men $39.8 \%$, women $60.2 \%$ ) from the online survey, carried out in the frame of the National research program, project Nr. VPP-COVID2020/1-0011, was used in this study. The results showed that less compliant with COVID-19 epidemiological requirements were males, rural inhabitants, persons aged less than 60 years old, unemployed, with lower education level, and those, who are less afraid of COVID-19 and think that its dangerousness is exaggerated. Compliance with the restrictions did not relate to the marital and parental status. Based on this study, policy suggestions were made regarding a more targeted way of the providing important information on the preventive behaviour to reduce the spread of the virus.
\end{abstract}

\section{Introduction}

Due to the outbreak of Covid-19 coronavirus disease, the World Health Organization (WHO) declared an international public health emergency on 30 January 2020, as the disease, first reported by China in December 2019, continued to spread severely across all continents, affecting countries around the world as the burden of disease increased. Since the spring, a number of nations around the world, including Latvia, have declared a state of emergency, with specific government restrictions developed in cooperation with WHO, to reduce spread of the COVID-19. For example, using face mask and hand sanitizer, keep social/physical distance, $2+2$ rule which means 2 people in 2 square metres. People were not allowed to visit friends, relatives, cultural and sporting events were suspended, which may have caused psychological stress because they had not experienced anything like that before.

According to Zitek and Schlund [1], people with a higher psychological entitlement strive to avoid actions that could hurt them, but their high expectations, lack of compassion for others, and distrust of authoritative people may influence their judgments of the coronavirus risks and the benefits of following safety requirements. In addition, people with higher psychological privileges felt that the threat of the virus was exaggerated and, accordingly, cared 
less about harming others, which explained their beliefs not to follow the restrictions [1]. In their research, Lams and his colleagues [2] discovered that during and after a pandemic, society faces psychological distress and physiological problems. Although the new life brought about by COVID-19 has transformed many of our routines, attitudes, and assumptions, it has also had a negative impact on mental health of people, according to Koçak and colleagues in their study [3].

Researchers Nosratabadi and Halvaiepour [4] found some researches [5, 6] that discuss the role and importance of cognitive and perceptual beliefs in the acceptance of disease prevention behaviours. Researchers [4] talk about the fact that many people make their choices based on cognitive bias. Cognitive bias is a construct based on misconceptions or distortions that, due to certain aspects of objective truth, lead to systematically distorted perceptions, such as prejudice. Stanovich with colleagues [7] found out that prejudice affects everyday life, choices and actions.

The aim of this study is to examine socio-psychological profile of Latvian inhabitants who did not comply with the COVID-19 epidemiological requirements. Thus, to figure out who and what kind of people did not follow the government's restrictions. Two questions were raised in this study: 1) what are the socio-demographic characteristics of individuals who did not comply with the Covid-19 epidemiological requirements? 2) What are the psychological characteristics of individuals who did not comply with the Covid-19 epidemiological requirements?

\section{Method}

Participants and procedure. Secondary data from the survey $(N=2608$, men $39.8 \%$, aged 18-74) carried out in July 2020, randomized nationally representative sample, in the frame of the National research program (VPP-COVID-2020/1-0011) was used in this study. The data collection was carried out by the international market, public opinion and media research company Kantar in July. Respondents were sent an individual invitation with a password and a link to the questionnaire on the Internet (in Latvian or Russian, according to the respondent's choice). Respondents filled in the questionnaire at their preferred time, but according to the "closing" date set by "Kantar". Completed questionnaires were immediately stored on the Kantar server. After the "closing" of the survey data processing and analysis of the results took place.

Measures. From the full survey only some socio-demographic questions (age, gender, education level (primary education or lower, secondary school education or similar, Bachelor's, Masters or Doctoral degree), living place (urban or rural), employment status (working, pensioner, unemployed, homemaker, allowance or pension due to health condition, student), marital status (single, married or in a civil marriage, divorced, live with the person you are in a relationship with, widow)), were used in this study to determine social characteristics. The following questionnaires and questions were used to determine psychological characteristics:

1. Composite measure of Fear of COVID-19 (Perepjolkina, Mārtinsone, Kolesnikova, 2020). Two items, for example, “Are you afraid of contracting the coronavirus?", Likert scale (1 disagree to 5 - agree), Cronbach's alpha 0,74.

2. Composite measure of COVID-19 Risk perception (Perepjolkina, Mārtinsone, Kolesnikova, 2020). Four items, for example, "Such a virus does not exist at all", Likert scale ( 1 - disagree to 5 - agree), Cronbach's alpha 0.87 .

3. Psychological resilience survey (Perepjolkina, Mārtinsone, 2020). Seven items, Likert scale (1 - disagree to 5 - agree), Cronbach's alpha 0.87 . 
4. Successful emotion regulation (Emotion Regulation Skills Questionnaire; ERSQ-27, Berking \& Znoj, 2008; adaptation in Latvian did Paiča, Mārtinsone, 2019). Likert scale (0 - never to 4 - almost always), Cronbach's alpha 0.96 .

5. Social Problem-Solving Inventory (Revised version; SPRP-S, D’Zurilla \& Nezu, 2007; adaptation in Latvian did Kolesnikova, 2007). Two subscales were used in this study: 1) Positive problem orientation subscale (5 items, Likert scale (1 - disagree to 5 - agree), Cronbach's alpha 0,$86 ; 2$ ) Negative problem orientation subscale ( 5 items, Likert scale ( 1 - disagree to 5 - agree), Cronbach's alpha 0.85 .

6. As the main variable the statement: "According to the instructions given by WHO, it is necessary for some precautions to be taken in order to prevent the spread of the virus. Do you believe that you take adequate precautions?" were used in this study (response rate from 1 = "not at all" to 5 = "very much").

Data analysis. SPSS 24 version was used in the data processing process. Descriptive statistics, Student T-test, Chi square test, Pearson correlation were used in this data analysing process.

\section{Results}

The first figure shows the results of the gender differences in the study participants for those who did not comply with the requirements. The results showed that there were statistically significant differences between the gender, $t=-7.40, p<0.001$. The data show that women are more likely to comply with the requirements (see Fig. 1). Statement ${ }^{1}$ "According to the instructions given by WHO, it is necessary for some precautions to be taken in order to prevent the spread of the virus. Do you believe that you take adequate precautions?"

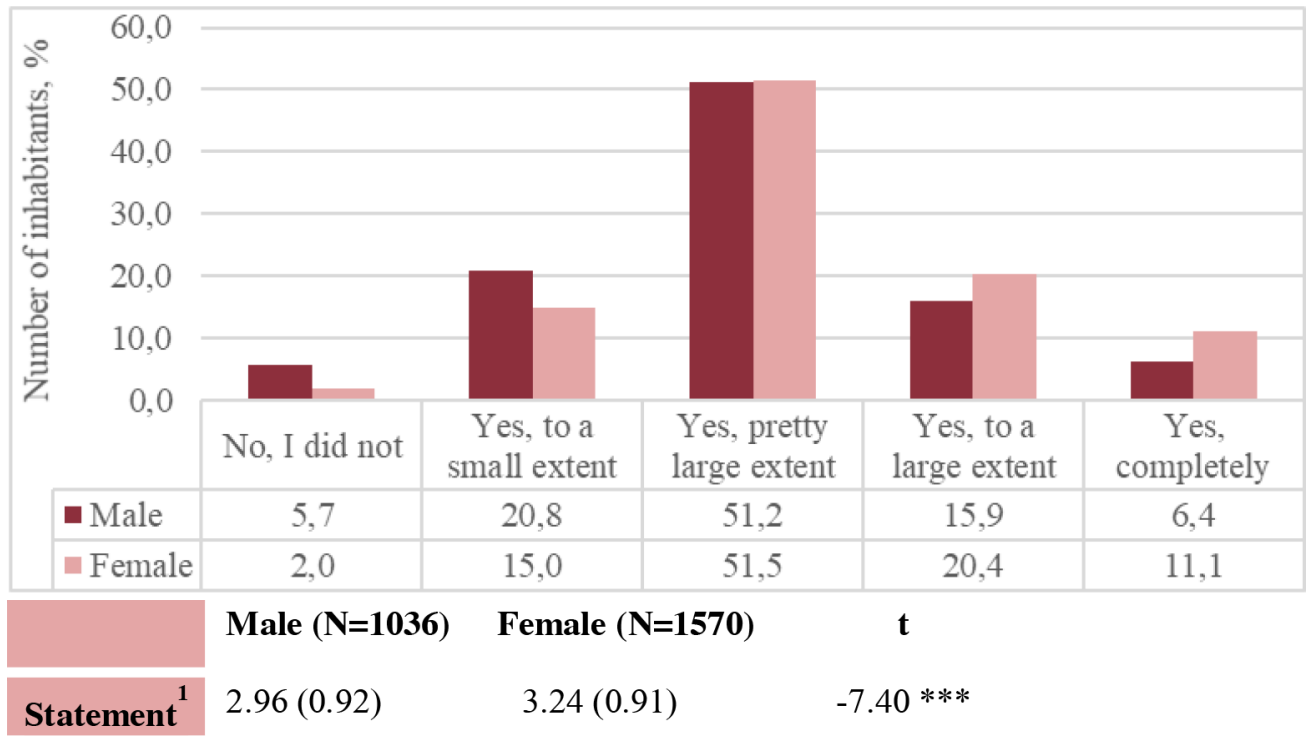

Figure 1. Distribution of answers to the question about people who did not comply with the requirements in a group of men and women.

The second figure shows the results that there are statistically significant differences between the responses of people living in urban and rural areas (see Fig. 2). The obtained data 
indicate that the residents living in the city slightly more likely to comply with the requirements, compared to the residents living in rural areas, $t=2.61, p<0.01$.

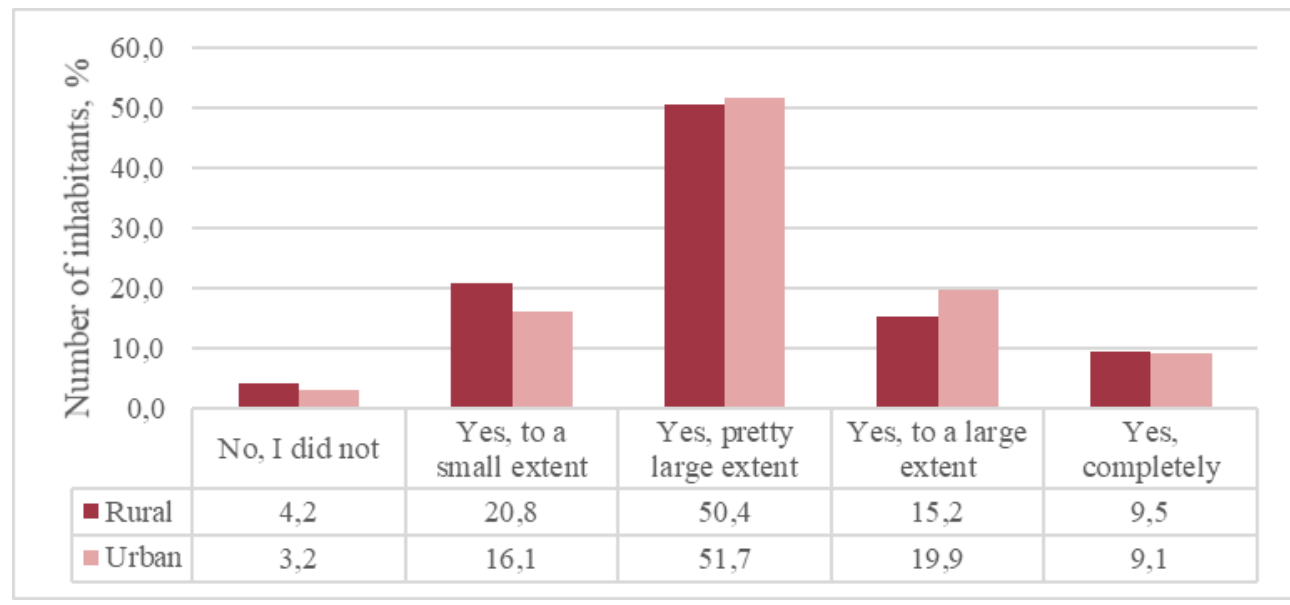

Urban (N=1910) Rural (N=698)

Statement
$3.16(0.91)$
$3.05(0.95)$ $\mathbf{t}$

$2.61 * *$

Figure 2. Distribution of answers to the question about people who did not comply with the requirements depending on the place of residence (urban/rural area).

Next results show that there are statistically significant differences between the responses of people's age group, Welch's F $(5,2278)=4.63, p<0.001$ (see Fig. 3). There are statistically significant differences between age groups (based on the PostHoc Tamhane test): 60-69 and 30-39, $p<0.05 ; 60-69$ and 40-49, $p<0.05 ; 60-69$ and 50-59, $p<0.01 ; 70$ and older and 30-39, $p<0.01 ; 70$ and older and 40-49, $p<0.01 ; 70$ and older and 50-59, $p<0.01$.

The fourth figure shows the results that there are statistically significant differences between the responses of employment status, Welch's $\mathrm{F}(5,257)=6.50, p<0.001$ (see Fig. 4). There are statistically significant differences between groups based on employment status (based on the PostHoc Tamhane test): Pensioner and working, $p<0.001$; Pensioner and unemployed, $p<0.01$.

The fifth figure shows the results of the study participants' differences in responses of those who did not comply with the requirements depending on their level of education. There are statistically significant differences between groups. The higher the level of education, the more people comply with the requirements, Welch's $\mathrm{F}(4,184)=8.51, p<0.01$ (see Fig. 5).

There are no statistically significant differences between groups depending on marital status. Even when we divided into two groups (In relationships or Single), still there are no statistically significant differences.

The first table shows the results of the relationship between psychological indicators and those who did not comply with the requirements. The results show that there is a statistically significant but weak positive relationship between participants who comply with the requirements and positive problem orientation $(r=0.145, p<0.01)$, psychological resilience $(r=0.082, p<0.01)$, fear of Covid-19 $(r=0.282, p<0.01)$, successful emotion 


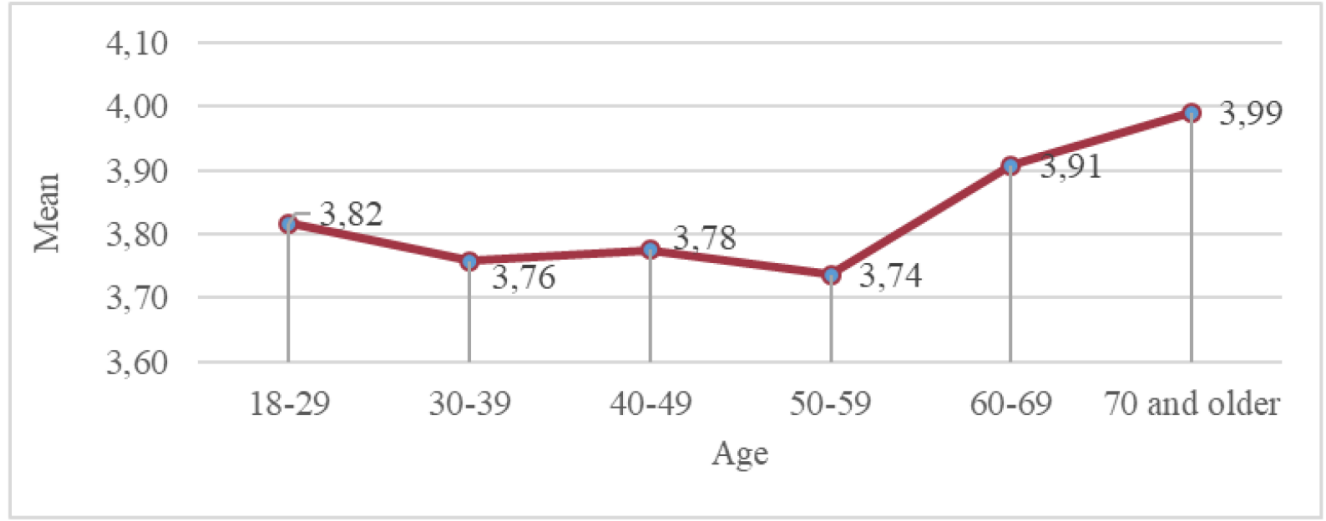

Figure 3. Distribution of answers to the question about people who did not comply with the requirements depending on age group.

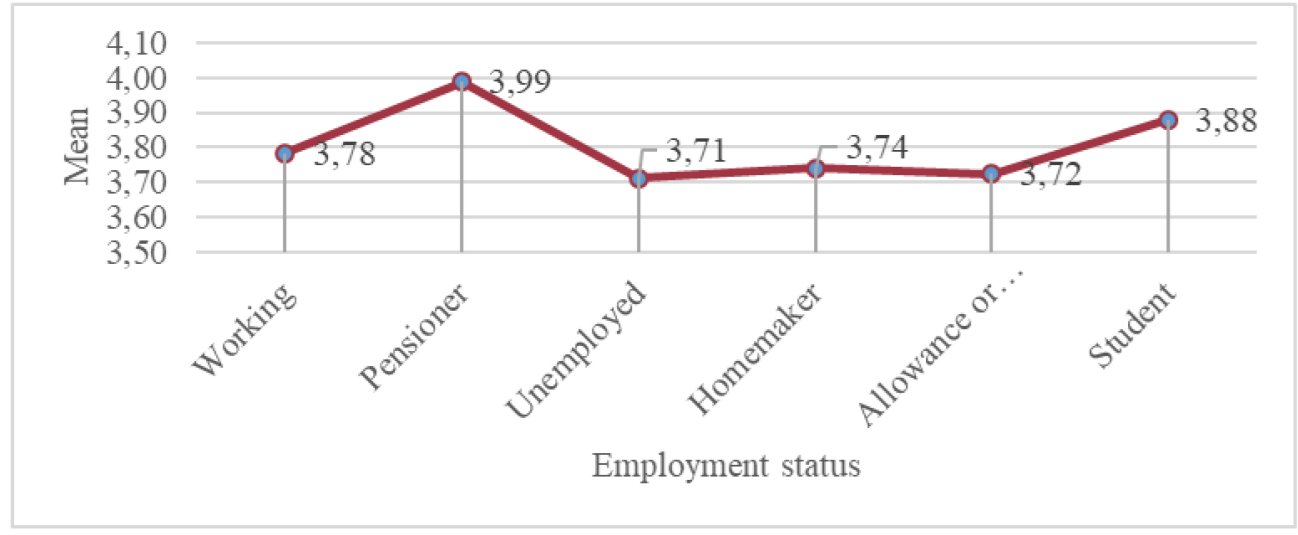

Figure 4. Distribution of answers to the question about people who did not comply with the requirements depending on employment status.

regulation $(r=0.162, p<0.01)$, risk perception $(r=0.264, p<0.01)$. The results show that there is no statistically significant relationship between participants who comply with the requirements and negative problem orientation $(r=-0.019, p=0.01)$.

\begin{tabular}{lc}
\hline Psychological indicators & Statement $^{1}$ \\
Positive problem orientation & $0.145^{* *}$ \\
Psychological resilience & $0.082^{* *}$ \\
Fear of Covid-19 & $0.282^{* *}$ \\
Successful emotion regulation & $0.162^{* *}$ \\
Risk perception & $0.264^{* *}$ \\
Negative problem orientation & -0.019 \\
\hline
\end{tabular}

**. Correlation is significant at the 0.01 level (2-tailed).

Statement 1 "According to the instructions given by WHO, it is necessary for some precautions to be taken in order to prevent the spread of the virus. Do you believe that you take adequate precautions?" 


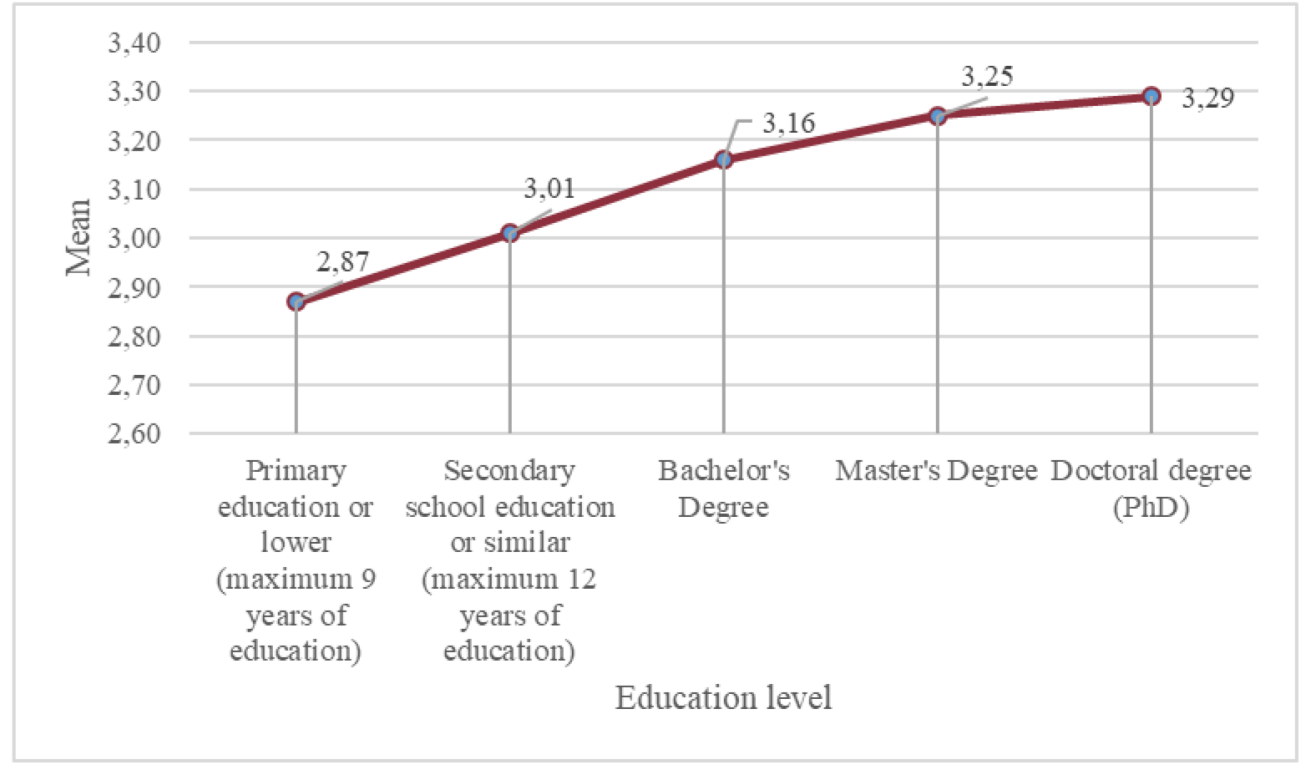

Figure 5. Distribution of answers to the question about people who did not comply with the requirements depending on the level of education.

\section{Conclusions}

According to the results of this study, we can conclude that the socio-psychological profile of the Latvian inhabitants who did not comply with the epidemiological requirements set by the government are as follows: men, aged 30-60, live in rural areas, have a low education level (the lower the level of education, the less restrictions are observed), not afraid of Covid-19, have low level of risk perception and psychological resilience, do not control their emotions, and are not focused on positive problem solving style. The data obtained from this study are retrospective when the situation of Covid-19 in the country was calm. It would be necessary to obtain data on the current situation and compare it with retrospective data.

\section{Discussion}

The results of this study show that women are more likely to comply with the Covid-19 requirements than men are. These results are consistent with Nivette and his colleagues research [8]. Nivette with his colleagues explains these results by the fact that men have a lower level of trust in the government and its restrictions. As a result, based on Global health [9] statistics, men have a higher mortality rate than women due to Covid19.

The results of the research show that those living in Latvia cities observe restrictions more than in rural areas. These results could be explained by the fact that the population is more aware of the restrictions, forced to spend more time at home, because shops and amusement parks are closed, sports and cultural activities are suspended, there is no way to spend their free time. On the other hand, people living in rural areas go outside, spend time with relatives, because the perception of the risk of the virus is low, and there exists possible belief that it will not reach the countryside. My guess would be that this is due to population density. A city has a higher risk of developing Covid-19. 
The results of this study showed that older people (60+) more likely comply with the Covid-19 requirements than people below 60 years do. These results are in line with the study of Zhao and his colleagues [10]. These researchers explain this result with previous research [11] by Zhou and his colleagues by saying that epidemiologists had previously informed the public that the virus was more life-threatening in the elderly, which had resulted in compliance.

The results of this study show that people who are in retirement and not in employment more likely comply with the requirements. These results are in line with the findings of Zhao and his colleagues [10], and they explain this by the fact that people who do not need to go to work, and are economically inactive, are more compliant.

The results of this study show that people with higher level of education more likely to comply with the requirements. However, these results contradict the findings of Dukhi and her colleagues [12] that people are more aware of restrictions that have a lower level of education. In contrast, Labban [13] found that people with a higher level of education have a greater understanding of COVID-19 because they have more knowledge and understanding of the disease, resulting in looking for ways to take preventative action and are more compliant.

There are no statistically significant differences between groups depending on marital status.

The results showed a statistically significant positive but weak relationship between adherence to restrictions and positive problem solving, psychological resilience, fear of covid-19, and risk perception. Several previous studies have shown an association between fear of Covid-19 and preventive behaviour as a constraint, such as the Chang, Harper, Anaki, and Sergay studies [14-16]. Harper's study [15] revealed that the more afraid a person is, the more he/she adheres to restrictions, these people worry about their health. The results of positive problem solving could be interpreted as the fact that those people who are prone to problem solving, are optimistic about solving the problem, those people are more likely to comply with the Covid-19 requirements. Those people with a high level of psychological resilience and risk perception are more likely to comply with the Covid-19 requirements. These people are mentally and emotionally ready for the virus, respectively, to comply with the requirements. Residents with a higher risk perception, treat the situation responsibly, do not want to risk with their and relative's health, therefore take preventive actions and observe restrictions.

One of the main limitations of this study was that the data were collected in the summer of 2020, when the situation of Covid-19 in the world, including Latvia, was much calmer than in the spring, as the survey asked to retrospectively assess whether a participant did comply with the Covid-19 requirements, just when the state of emergency was declared. Another limitation of the study was the use of secondary data, and it was only possible to analyze the variables that were available in the data set. One of the strengths of the study is the number of participants, as a nationally representative sample was used.

The study was conducted by the State Research Program "Impact of COVID-19 on health care system and public health in Latvia; ways in preparing health sector for future epidemics" (project No. VPPCOVID-2020 / 1-0011) within the sub-project "Impact of the Covid-19 epidemic on the health care system and public health in Latvia".

\section{References}

[1] E.M. Zitek, \& R.J. Schlund. Personality and individual differences 171, 110491 (2021)

[2] M.H.B. Lam, Y.K. Wing, M.W. M. Yu, C.M. Leung, R.C. Ma, A.P. Kong, \& S.P. Lam. Archives of internal medicine 169(22), 2142-2147 (2009) 
[3] O. Koçak, Ö.E Koçak, \& M.Z. Younis. International journal of environmental research and public health 18(4), 1836 (2021)

[4] M. Nosratabadi, \& Z. Halvaiepour. Integrative Psychological and Behavioral Science, 1-16 (2021)

[5] S. Julinawati, D. Cawley, C. Domegan, M. Brenner, \& N.J. Rowan. Journal of Asian Scientific Research 3(6), 677-692 (2013)

[6] M.Y. Kim, \& Y.J. Kim. The Open Nursing Journal 12, 106 (2018)

[7] K.E. Stanovich, W.C. Sá, \& R.F. The nature of reasoning (375-409) (2004)

[8] A. Nivette, D. Ribeaud, A.L. Murray, A. Steinhoff, L. Bechtiger, U. Hepp, \& M. Eisner. SocArXiv (2020)

[9] Global Health 50/50, 2020. COVID-19 Sex-Disaggregated Data Tracker: Sex, Gender, and COVID-19. Available: http://globalhealth5050.org/covid19/

[10] S.Z. Zhao, J.Y.H. Wong, Y. Wu, E.P.H. Choi, M.P. Wang, \& T.H. Lam. International journal of environmental research and public health 17(18), 6692 (2020)

[11] F. Zhou, T. Yu, R. Du, G. Fan, Y. Liu, Z. Liu, \& B. Cao. The lancet 395(10229), 1054$1062(2020)$

[12] N. Dukhi, T. Mokhele, W.A. Parker, S. Ramlagan, R. Gaida, M. Mabaso, \& P. Reddy. The Open Public Health Journal 14(1), (2021)

[13] L. Labban, N. Thallaj, \& A. Labban. Arch Med 12(2), 8 (2020)

[14] K.C. Chang, C. Strong, A.H. Pakpour, M.D. Griffiths, \& C.Y. Lin. Journal of the Formosan Medical Association 119(12), 1772-1780 (2020)

[15] C.A. Harper, L.P. Satchell, D. Fido, \& R.D. Latzman. International journal of mental health and addiction, 1-14 (2020)

[16] D. Anaki, \& J. Sergay. Worldwide survey results from early March 2020. Plos one 16(1), (2021) 